\title{
Mycosis fungoides: reflectance confocal microscopy and its role in the diagnosis

Ana Carolina Porto ${ }^{*}$ (D) Tatiana Pinto Blumetti, Adriana Silveira Pessoa Mendes, João Pedreira Duprat Neto, Gisele Gargantini Rezze and Juliana Casagrande Tavoloni Braga

\begin{abstract}
Background: Mycosis fungoides (MF), a T-cell lymphoma, is the most common variant of primary cutaneous lymphomas. The discrete clinical aspect of the early patch-stage and an overlapping clinical presentation with other erythematosquamous skin diseases make the diagnosis of MF challenging. Histopathology is the gold standard for the diagnosis of MF. However, in early stages, MF can simulate inflammatory diseases, presenting reactive lymphocytes and absence of lymphocytic cytologic atypia. Consecutive biopsies are often necessary from several clinically suspect sites. Previous studies evaluated Reflectance Confocal Microscopy (RCM) as a promising tool for MF diagnosis because it offers the opportunity to analyze skin structures non-invasively at a 'quasi-histopathologic' resolution and to guide the most representative site for biopsy.

Case presentation: We present a 76 years-old woman with a 5-year history of erythematous plaques and patches. She had had 5 previous skin biopsies with a pattern suggestive of nummular eczema. The history and the clinical presentation led to the suspicion of MF. RCM examination was performed and two lesions were marked for biopsy. The histopathology exam confirmed the diagnosis of MF. The patient was submitted to topical treatment with total remission of the lesions.

Conclusions: The mean time from onset of symptoms to diagnosis is 6 years and the delay in diagnosis results in delay for adequate therapy. Therefore, the selection of the biopsy site is crucial to avoid unrepresentative samples. Mancebo et al. recently published the largest cohort of cutaneous T.cell lymphoma examined with RCM. 83 lesions were evaluated, and the authors confirmed that this image technique was effective in to guide the most representative site for the biopsy. We believe that further and larger studies will clarify it and defining a diagnostic algorithm for the RCM diagnosis of MF.
\end{abstract}

Keywords: Reflectance confocal microscopy, Mycosis Fungoides, Early diagnosis

\section{Background}

Mycosis fungoides (MF), a T-cell lymphoma, is the most common variant of primary cutaneous lymphomas. The classic presentation of MF are erythematosquamous patches and plaques in non-photo exposed areas. However, a discrete clinical aspect of early patch-stage MF and an overlapping clinical presentations with other erythematosquamous skin diseases, can make the diagnosis of MF challenging [1,2].

\footnotetext{
* Correspondence: carolsporto1@hotmail.com

Cutaneous Oncology Department, AC Camargo Cancer Center, Rua Prof. Antônio Prudente, 211, Sao Paulo 01509-010, Brazil
}

\section{Case presentation}

We present a case of a 76 years-old woman with a 5 -year history of erythematous plaques and patches on arms, which in the last 2 years have progressed to trunk and thighs (Fig. 1). The patient had had 5 previous skin biopsies that revealed a lymphocytic reactive pattern suggestive of nummular eczema. The history of progressive evolution of the cutaneous lesions, in addition to their clinical appearance, led to the suspicion of parapsoriasis and MF. Reflectance Confocal Microscopy (RCM) was performed in order to evaluate the lesions noninvasively.

Five lesions located in different skin sites were analyzed; two of them presented an epidermal disarray with bright cells infiltrate suggestive of lymphocytes and hyporeflective papillae at the dermo epidermal junction (DEJ). The

(c) The Author(s). 2018 Open Access This article is distributed under the terms of the Creative Commons Attribution 4.0 International License (http://creativecommons.org/licenses/by/4.0/), which permits unrestricted use, distribution, and 


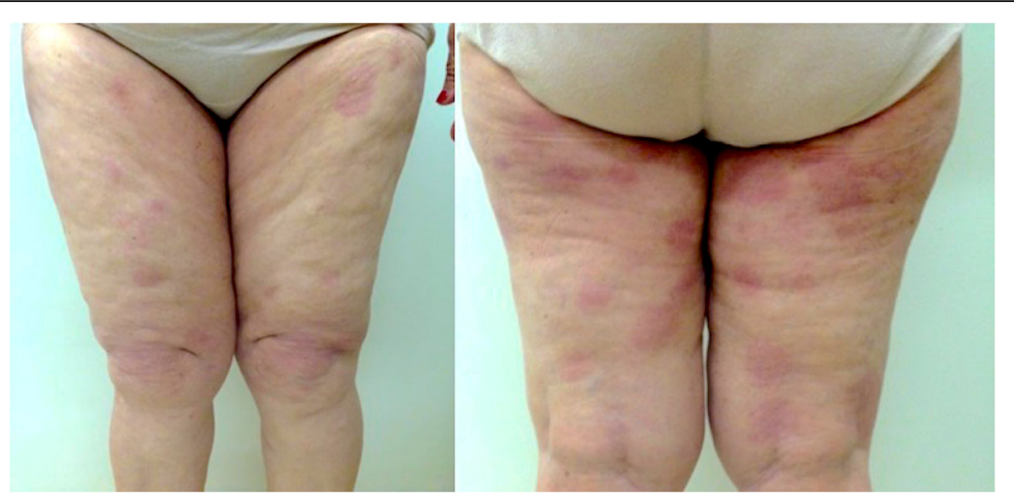

Fig. 1 Clinical images of mycosis fungoides patch stage

most suspicious sites on MC examination were marked for the biopsy. The histopathology exam, complemented by immunohistochemistry, confirmed the diagnosis of MF (Figs. 2 and 3). The patient was submitted to topical treatment with total remission of the lesions. She has been in remission of the disease for 3 years.

\section{Discussion and conclusions}

The histopathology exam, complemented by immunohistochemistry, is still the gold standard for the diagnosis of MF, and it's based on the presence of atypical lymphocytes with cerebriform nuclei, surrounded by clear cytoplasm, arranged in band in the papillary dermis and in the DEJ. In early stages of MF, histopathologic findings can simulate inflammatory diseases, presenting only with reactive lymphocytes and with absence of lymphocytic cytologic atypia, as seen in this clinical presentation. Pautrier micro-abscesses are cluster of atypical lymphocytes in an epidermotropism distribution. Pautrier micro-abscesses are the pathognomonic findings in the histopathology exam of MF, but are only seen in $25 \%$ of cases, present mostly in advanced lesions

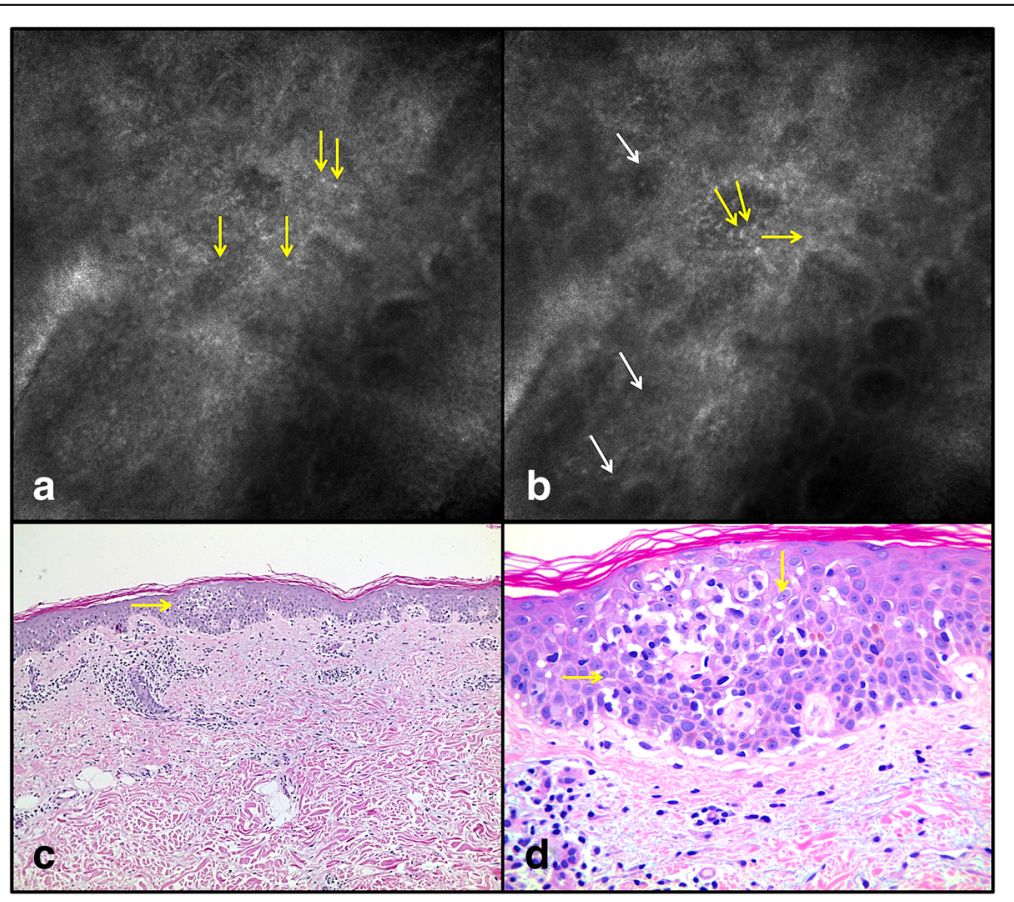

Fig. 2 a Individual Reflectance Confocal Microscopy $(R C M)$ image $(0.5 \times 0.5 \mathrm{~mm})$ showing at the dermo-epidermal junction (JDE) level bright cells infiltrate in the middle of the keratinocytes suggestive of lymphocytes (yellow arrow). b Individual RCM image showing at the JDE level bright cells infiltrate in the papillae suggestive of atypical lymphocytes (yellow arrow) and hyporeflective papillae (white arrow). c Haematoxylin and eosin (H\&E) histopathological panoramic view of the lesion: an infiltrate of lymphocytes in the papillary dermis and epidermotropism of atypical lymphocytes (yellow arrow). d H\&E section: epidermotropism of atypical lymphocytes (yellow arrow). Original magnifications: c, X40; DX400 


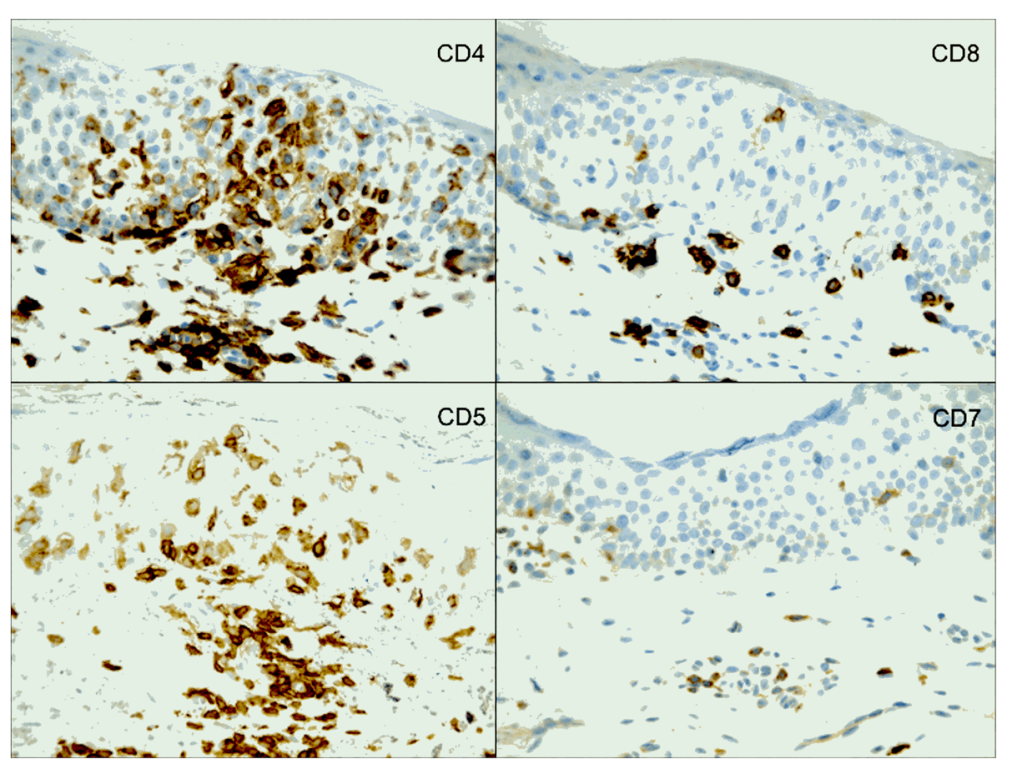

Fig. 3 Immunohistochemistry profile of mycosis fungoides showing T cell lymphocytes that express the phenotype CD4 $4^{+}, C D 8^{-}$, and loss of the surface antigens CD5 and CD7. Original magnifications X400

of plaque-stage MF $[1,3]$. Furthermore, there is also great heterogeneity between the lesions: two or more simultaneous biopsies in different suspicious lesions usually reveals different histopathological aspects.

Thereby, consecutive biopsies are often necessary from several clinically suspect sites and it can make the diagnosis of initial MF challenging. The mean time from onset of symptoms to diagnosis is 6 years and the delay in diagnosis results in delay for adequate therapy [2]. Therefore, the selection of the biopsy site is crucial to avoid unrepresentative samples [3].

Previous studies have evaluated reflectance confocal microscopy (RCM) as a promising tool for MF diagnosis because it offers the unique opportunity to analyze skin structures non-invasively at a 'quasi-histopathologic' resolution and to guide the most representative site for the biopsy [3, 4].

Koller et al. $l$ reported that RCM examination of MF lesions revealed an interface dermatitis and an infiltration of the upper epidermal layers by roundish cells, distributed in nests or diffusely widespread throughout the epidermis. These authors referred a sensitivity of $63,33 \%$ and a specificity of $92,89 \%$ for MF diagnosis and concluded that RCM can be used as a supportive tool to determine the best location for taking a punch biopsy [5].

$\mathrm{Li}$ et al. reported a series of RCM features of MF which showed correlation with histopathological evaluation, from 10 patients with MF. In this study, dermal papillary rings were weak reflected light in all skin lesions evaluated and the authors believed that it occurs due to infiltration of atypical lymphocytes. Disarray of honeycomb of stratum; round to oval cells diffusely widespread throughout the epidermis and in the papillary dermis; infiltration of inflammatory cells in superficial dermis were others features reported [4].

Mancebo et al. recently confirmed previously reported RCM features of MF, with the largest cohort of cutaneous T.cell lymphoma examined with RCM. The authors evaluated 83 lesions of 41 patients with MF and epidermal disarray was observed in $88 \%$, lymphocytes in the epidermis in $86 \%$, vasodilation in $79 \%$ and hyporeflective papillae in $72 \%$. The papillae become hyporeflective by the presence of atypical lymphocytes interspersed. Pautrier's abscess lesions, seen as MCs as small round, dark holes filled with small, round and hyporeflective cells, are more likely to represent diagnostic features of MF to histopathology and were present in $53 \%$ of the lesions [6].

Confocal microscopy showed to be potentially effective in improving accuracy in the diagnosis of mycosis fungoides with the potential to save multiple or sequential skin biopsies. We believe that further and larger studies will clarify it and defining a diagnostic algorithm for the RCM diagnosis of MF.

\section{Abbreviations}

DEJ: dermo epidermal junction; MF: Mycosis fungoides; RCM: Reflectance Confocal Microscopy

Availability of data and materials

"Please contact author for data requests.".

\section{Authors' contributions}

All collaborators have made substantial contributions to the paper. ACP, TPB wrote the initial manuscript, ASPM have edited the text and the images and JPDN, GGZ e JCTB made the critical review. All authors read and approved the final manuscript. 
Ethics approval and consent to participate

Not applicable.

\section{Consent for publication}

Term granted by the patient.

\section{Competing interests}

The authors declare that they have no competing interests.

\section{Publisher's Note}

Springer Nature remains neutral with regard to jurisdictional claims in published maps and institutional affiliations.

Received: 1 April 2018 Accepted: 3 July 2018

Published online: 12 July 2018

\section{References}

1. Jawed SI, Myskowski PL, Horwitz S, Moskowitz A, Querfeld C. Primary cutaneous T-cell lymphoma (mycosis fungoides and Sézary syndrome): part I Diagnosis: clinical and histopathologic features and new molecular and biologic markers J Am Acad Dermatol 2014 Feb;70(2):205.e1-205.16; quiz $221-2$.

2. Agero ALC, Gill M, Ardigo M, Myskowski P, Halpern AC, González S. In vivo reflectance confocal microscopy of mycosis fungoides: a preliminary study. J Am Acad Dermatol. 2007 Sep;57(3):435-41.

3. Lange-Asschenfeldt S, Babilli J, Beyer M, Ríus-Diaz F, González S, Stockfleth E, et al. Consistency and distribution of reflectance confocal microscopy features for diagnosis of cutaneous T cell lymphoma. J Biomed Opt. 2012 Jan;17(1):16001.

4. Li W, Dai H, Li Z, Xu A-E. Reflectance confocal microscopy for the characterization of mycosis fungoides and correlation with histology: a pilot study. Skin Res Technol. 2013 Aug;19(3):352-5.

5. Koller S, Gerger A, Ahlgrimm-Siess V, Weger W, Smolle J, HofmannWellenhof R. In vivo reflectance confocal microscopy of erythematosquamous skin diseases. Exp Dermatol. 2009 Jun;18(6):536-40.

6. Mancebo SE, Cordova M, Myskowski PL, Flores ES, Busam K, Jawed SI, et al. Reflectance confocal microscopy features of mycosis fungoides and Sézary syndrome: correlation with histopathologic and T-cell receptor rearrangement studies. J Cutan Pathol. 2016 Jun;43(6):505-15.

Ready to submit your research? Choose BMC and benefit from:

- fast, convenient online submission

- thorough peer review by experienced researchers in your field

- rapid publication on acceptance

- support for research data, including large and complex data types

- gold Open Access which fosters wider collaboration and increased citations

- maximum visibility for your research: over $100 \mathrm{M}$ website views per year

At BMC, research is always in progress.

Learn more biomedcentral.com/submissions 